\title{
Syntheses and Fundamental Properties of Fe-rich Metastable Phase Alloys with Saturation Magnetization Exceeding 1.9 T
}

\author{
Ye Han ${ }^{a}$, Fanli Kong ${ }^{b}$, Chuntao Chang, Shengli Zhu ${ }^{a}$, \\ Sergey Ketov ${ }^{d}$, Dmitri Louzguine ${ }^{d}$, Akinisa Inoue ${ }^{a, d}$ \\ ${ }^{a}$ School of Materials Science and Engineering, Tianjin University, Tianjin 300072, China \\ ${ }^{b}$ International Institute of Green Materials, Josai International University, Togane 283-8555, Japan \\ ${ }^{c}$ Ningbo Institute of Materials Technology \& Engineering, Chinese Academy of Sciences, \\ Ningbo 315201, China \\ ${ }^{d}$ WPI Advanced Institute for Materials Research, Tohoku University, Sendai 980-8577, Japan
}

Received: September 30, 2014; Revised: August 4, 2015

\begin{abstract}
A melt-spun $\mathrm{Fe}_{90} \mathrm{Si}_{5} \mathrm{~B}_{5}$ alloy ribbon consists of bcc- $\mathrm{Fe}(\mathrm{Si})+\mathrm{Fe}_{3} \mathrm{~B}+$ amorphous phase and exhibits good bending ductility, high tensile fracture strength above $1000 \mathrm{MPa}$, high corrosion resistance and unique magnetic properties as exemplified for high saturation magnetization exceeding $1.9 \mathrm{~T}$, moderately high initial permeability of about 150 and low coercivity of $745 \mathrm{~A} / \mathrm{m}$ which are attractive for magnetic sensors utilizing a nearly constant high permeability with applied field up to coercivity. Besides, the tensile fracture strength and elongation increase significantly to $1286 \mathrm{MPa}$ and $0.62 \%$, respectively, after annealing for $900 \mathrm{~s}$ at $823 \mathrm{~K}$. The Fe-Si-B alloy ribbons are attractive as a new type of sensor material with features of high bending ductility, high tensile strength and elongation, relatively good corrosion resistanceand unique soft magnetic properties with very high saturation magnetization.
\end{abstract}

Keywords: amorphous alloy, corrosion behaviour, soft magnetic materials

\section{Introduction}

It is known that Fe-based amorphous and glassy alloys prepared by melt spinning exhibit good soft magnetic properties with relatively high saturation magnetization and have been used as soft magnetic materials such as transformer cores, inductors, magnetic field sensors and etc ${ }^{1-5}$. Although Fe-based amorphous and glassy alloys have already gained real application fields, further efforts have been devoted to improve fundamental properties such as glass-forming ability, amorphous or glass formation ranges, mechanical strength, corrosion resistance and magnetic properties for Fe-based amorphous and glassy alloys even nowadays ${ }^{6-8}$. For instance, the saturation magnetization for amorphous alloys increases steadily from $1.53 \mathrm{~T}$ for conventional amorphous alloys to $1.63 \mathrm{~T}$ for a new type of amorphous alloy ${ }^{9}$. More recently, the higher saturation magnetization reaching about $1.7 \mathrm{~T}$ in conjunction with low coercivity below $5 \mathrm{~A} / \mathrm{m}$ has been attained for new Fe-based alloy ribbons with a thickness up to about $50 \mu \mathrm{m}^{[10]}$. The new Fe-based alloys are located in a maximum Fe-rich concentration range and the further increase in $\mathrm{Fe}$ content causes significant decrease in soft magnetic properties as well as the loss of good bending ductility for the melt-spun ribbons ${ }^{11}$. The brittle nature reduces significantly the engineering value as soft magnetic materials ${ }^{12,13}$.

On the other hand, the further increase of Fe content to about 88 at $\%$ is expected to cause good ductile nature and high mechanical strength through the structural change to bcc-Fe base phase including small amounts of compounds

*e-mail: hanye0704@yahoo.com and/or crystalline phase. In addition, the resulting Fe-rich crystal-based alloys are expected to exhibit higher saturation magnetization and rather large coercivity. Nowadays it is also important to develop a high saturation magnetization alloy with a nearly constant high permeability (slope) up to relatively high magnetic field corresponding to a moderately large coercivity ${ }^{14,15}$. This paper aims to examine the possibility of developing Fe-based alloys in Fe-Si-B system exhibiting high saturation magnetization, relatively high coercivity, high tensile strength, good ductility and high corrosion resistance through the formation of coexistent bcc-Fe and compound and/or amorphous phases and to investigate the relation between their fundamental properties and the melt-spun structure.

\section{Experimental Procedure}

Ternary Fe-Si-B alloys with Fe-rich atomic compositions of $\mathrm{Fe}_{90} \mathrm{Si}_{2.5} \mathrm{~B}_{7.5}, \mathrm{Fe}_{90} \mathrm{Si}_{5} \mathrm{~B}_{5}, \mathrm{Fe}_{90} \mathrm{Si}_{7.5} \mathrm{~B}_{2.5}, \mathrm{Fe}_{91} \mathrm{Si}_{4.5} \mathrm{~B}_{4.5}$ and $\mathrm{Fe}_{92} \mathrm{Si}_{4} \mathrm{~B}_{4}$ were chosen for the present study. Their alloy ingots were prepared by arc melting the mixtures of pure $\mathrm{Fe}$ (99.99 mass\%), Si (99.99 mass\%) and B (99.99 mass\%) in an argon atmosphere. Rapidly solidified ribbons were prepared by melt spinning with a copper wheel of $25 \mathrm{~cm}$ in diameter. The outer surface velocity of the wheel was about $40 \mathrm{~m} / \mathrm{s}$ and the resulting alloy ribbons have a thickness of about $18 \mu \mathrm{m}$ and a width of about 0.7 to $0.8 \mathrm{~mm}$. The structure was examined by $\mathrm{X}$-ray diffraction with $\mathrm{Cu}-\mathrm{K} \alpha$ radiation and transmission electron microscopy (TEM). Mechanical properties were 
measured by tensile testing machine (WDW-20) at room temperature. Tensile specimens had a gauge length of $10 \mathrm{~mm}$ and the strain rate was $0.04 \mathrm{~s}^{-1}$. Hardness was measured with a micro Vickers hardness tester with a load of $0.98 \mathrm{~N}$ (100gf). Bending ductility was evaluated by bending the specimen through 180 degrees. The bent surface was examined by scanning electron microscopy. Magnetic properties were measured with a VSM under an applied field of $800 \mathrm{kA} / \mathrm{m}$ and a B-H loop tracer under a field of $800 \mathrm{~A} / \mathrm{m}$. Corrosion behavior was evaluated for the ribbon samples which were degreased, washed and dried in air before immersion by electrochemistry test. Electrochemistry measurements were performed by an electrochemistry workshop (Gamry Reference 600 redefining electrochemical measurement) in $3.5 \mathrm{mass} \% \mathrm{NaCl}$ solution at $298 \mathrm{~K}$. Ribbon samples were set as working electrode; a platinum electrode was working as counter electrode and a saturated calomel electrode (SCE) was used as reference electrode. Polarization curves were measured by a potentiodynamic process from $250 \mathrm{mV}$ under open circuit potential (OCP) to $250 \mathrm{mV}$ above OCP value at a scanning rate of $1 \mathrm{mV} / \mathrm{s}$.

\section{Results and Discussion}

\subsection{Structure characterization}

Figure 1a shows XRD patterns of the melt-spun $\mathrm{Fe}_{90} \mathrm{Si}_{5} \mathrm{~B}_{5}$ alloy ribbon. The XRD patterns consist of only a bcc-Fe(Si,B) phase on the roll-contacted surface and a mixed phase of bcc- $\mathrm{Fe}(\mathrm{Si})$ and $\mathrm{Fe}_{3} \mathrm{~B}$ phases on the freely solidified surface, indicating that the cooling rate is lower for the freely solidified surface. Therefore, the subsequent data were always obtained from the freely solidified surface with lower cooling rates. $\mathrm{X}$-ray diffraction patterns of other Fe-Si-B alloy ribbons examined in the present study are shown in Figure $1 \mathrm{~b}$. The as-solidified structure is composed of bcc-Fe(Si,B) phase for $\mathrm{Fe}_{90} \mathrm{Si}_{7.5} \mathrm{~B}_{2.5}$ and $\mathrm{Fe}_{92} \mathrm{Si}_{4} \mathrm{~B}_{4}$ and bcc-Fe(Si)+ $\mathrm{Fe}_{3} \mathrm{~B}$ phases for $\mathrm{Fe}_{90} \mathrm{Si}_{2.5} \mathrm{~B}_{7.5}$ and $\mathrm{Fe}_{91} \mathrm{Si}_{4.5} \mathrm{~B}_{4.5}$. There is a clear tendency for the as-solidified structure to change from bcc- $\mathrm{Fe}(\mathrm{Si}, \mathrm{B})$ single phase to mixed bcc-Fe $(\mathrm{Si})+\mathrm{Fe}_{3} \mathrm{~B}$ phases with increasing concentration ratio of $\mathrm{B}$ to $\mathrm{Fe}$. The maximum solid solubility concentration of $\mathrm{B}$ to bcc-Fe( $\mathrm{Si}$ ) seems to be about 4 to 4.5 at $\%$ for 90 to 92 at $\% \mathrm{Fe}$. The lattice parameters of the bcc-Fe( $\mathrm{Si})$ and bcc-Fe( $\mathrm{Si}, \mathrm{B})$ phases measured from the peak positions in the X-ray diffraction patterns were $2.859 \mathrm{~nm}$ for $\mathrm{Fe}_{90} \mathrm{Si}_{5} \mathrm{~B}_{5}$ and $6.749 \mathrm{~nm}$ for $\mathrm{Fe}_{90} \mathrm{Si}_{7.5} \mathrm{~B}_{2.5}$, respectively. One can notice that the significant increase in the lattice parameter of bcc-Fe( $\mathrm{Si}, \mathrm{B})$ alloys. This is presumably due to the minor presence of secondary phase (amorphous or Fe-B compounds) and supersaturated with B element through the solution mechanism of B into interstitial sites.

In order to confirm the absence of $\mathrm{Fe}_{3} \mathrm{~B}$ phase, the more detailed X-ray diffraction patterns in the diffraction $2 \theta$ angle range of 41 to 49 degrees are shown in Figure 1c. The patterns of the $90 \% \mathrm{Fe}$ and $92 \% \mathrm{Fe}$ alloys consist of only bcc-Fe(Si,B) peak of (110) and no appreciable peak of $\mathrm{Fe}_{3} \mathrm{~B}$ is seen. Here it is notable that the bcc-Fe $(\mathrm{Si}, \mathrm{B})$ peak is rather broad, indicating the possibility that the as-quenched alloys include a trace of amorphous phase.

Figure 2 shows a bright field TEM image and selected-area electron diffraction patterns of the melt-spun $\mathrm{Fe}_{90} \mathrm{Si}_{5} \mathrm{~B}_{5}$ alloy.
The as-spun structure consists of bcc-Fe(Si)with a grain size of about 0.2 to $0.3 \mu \mathrm{m}$ and fine nearly spherical precipitates with a size of about $80 \mathrm{~nm}$. The diffraction patterns shown in Figure $2 \mathrm{~b}$ and 2(c) are identified as bcc-Fe and bct-Fe $\mathrm{B}$ phases, indicating that the fine precipitates are $\mathrm{Fe}_{3} \mathrm{~B}$ phase.

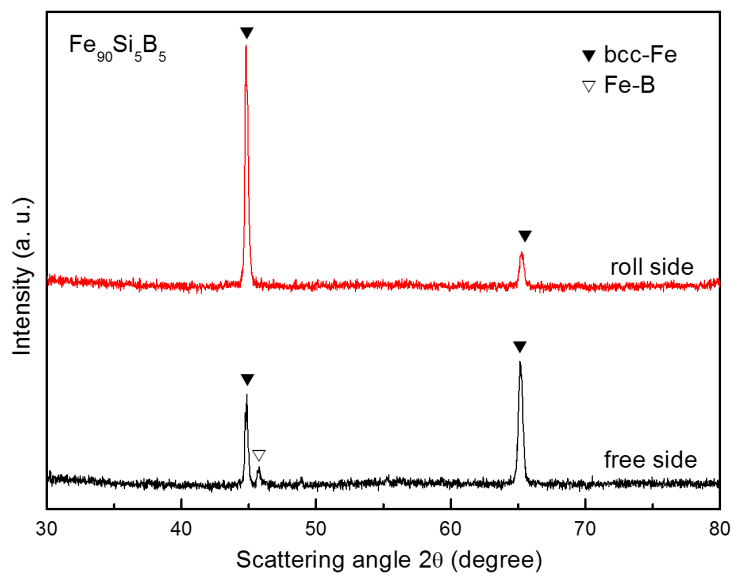

(a)

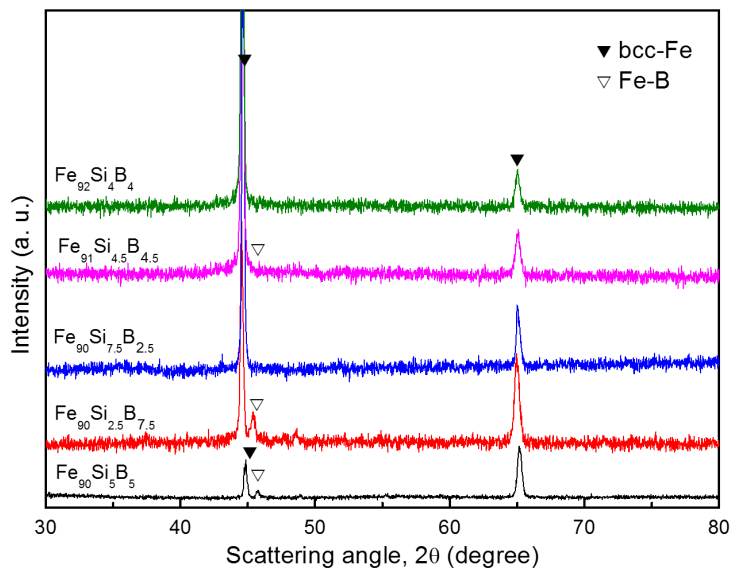

(b)

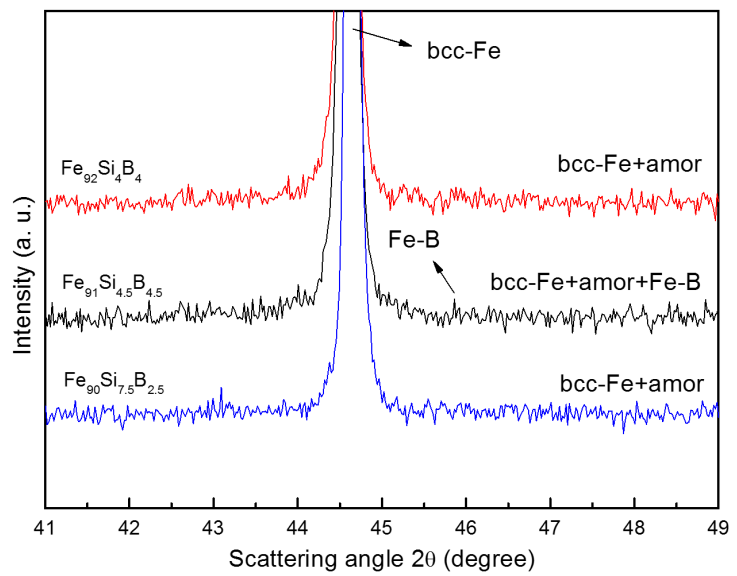

(c)

Figure 1. (a) XRD patterns ( $\mathrm{Cu}-\mathrm{K} \alpha, \lambda=1.5406)$ of $\mathrm{Fe}_{90} \mathrm{Si}_{5} \mathrm{~B}_{5}$ alloy ribbon measured on roll side and free side, respectively. (b) XRD patterns $(\mathrm{Cu}-\mathrm{K} \alpha, \lambda=1.5406)$ of $\mathrm{Fe}_{90} \mathrm{Si}_{5} \mathrm{~B}_{5}, \mathrm{Fe}_{90} \mathrm{Si}_{2.5} \mathrm{~B}_{7.5}, \mathrm{Fe}_{90} \mathrm{Si}_{7.5} \mathrm{~B}_{2.5}$, $\mathrm{Fe}_{91} \mathrm{Si}_{4.5} \mathrm{Si}_{4.5}$ and $\mathrm{Fe}_{92} \mathrm{Si}_{4} \mathrm{~B}_{4}$ alloy ribbon. (c) Details of XRD patterns from 41 to 49 degree of scattering angle $2 \theta$. 


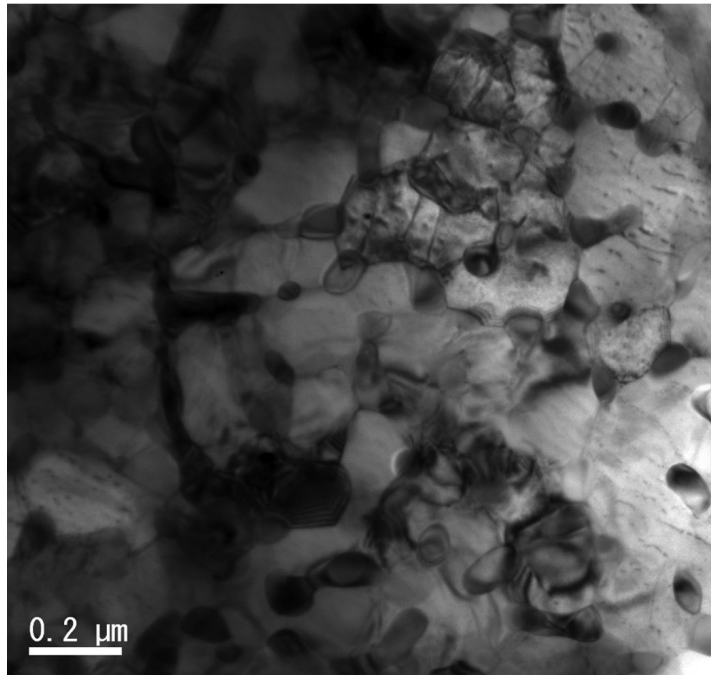

(a)

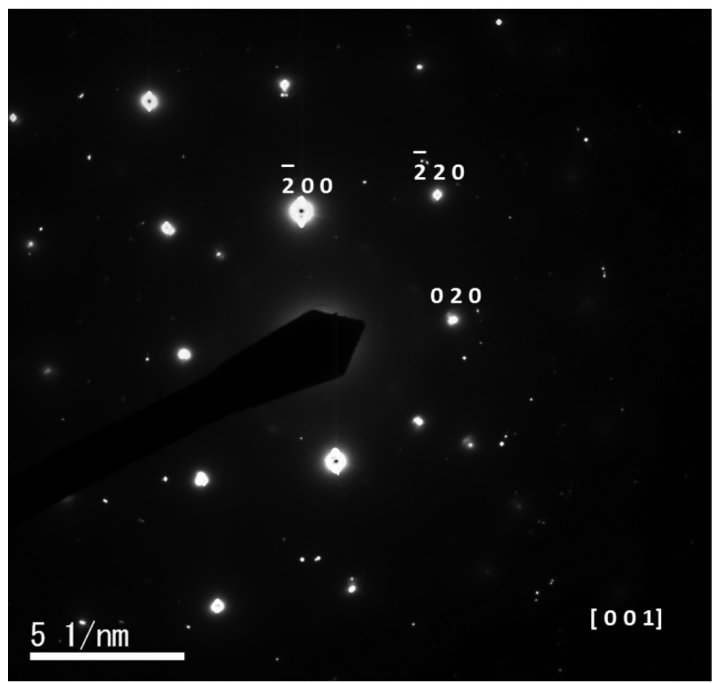

(b)

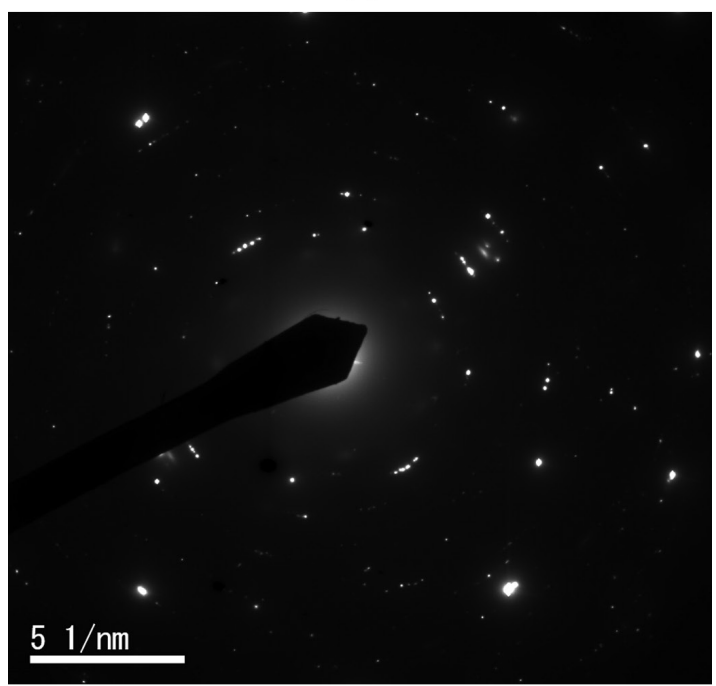

(c)

Figure 2. TEM images of $\mathrm{Fe}_{90} \mathrm{Si}_{5} \mathrm{~B}_{5}$ ribbon: (a) Bright-field image (b) SAED of bcc-Fe pattern; (c) SAED of $\mathrm{Fe}_{3} \mathrm{~B}$ ring pattern.
In addition, one can recognize halo ring patterns in some local areas in the melt-spun $\mathrm{Fe}_{90} \mathrm{Si}_{5} \mathrm{~B}_{5}$ alloy as exemplified in Figure $3 \mathrm{a}$. The dark field image taken from the ring reflection part is shown in Figure 3b. The image reveals a homogeneous contrast and no appreciable precipitates corresponding to a crystalline phase areseen. It is thus concluded that the as-spun structure consists of bcc- $\mathrm{Fe}(\mathrm{Si})+\mathrm{Fe}_{3} \mathrm{~B}+$ amorphous phases, being consistent with the results shown in Figure 1c.

\subsection{Mechanical properties}

All the as-spun ribbons except $\mathrm{Fe}_{90} \mathrm{Si}_{2.5} \mathrm{~B}_{7.5}$ exhibited good bending ductility. As an example, Figure 4 shows a SEM image of the outer bent surface of the $\mathrm{Fe}_{90} \mathrm{Si}_{5} \mathrm{~B}_{5}$ ribbon subjected to bending deformation through 180 degrees. A number

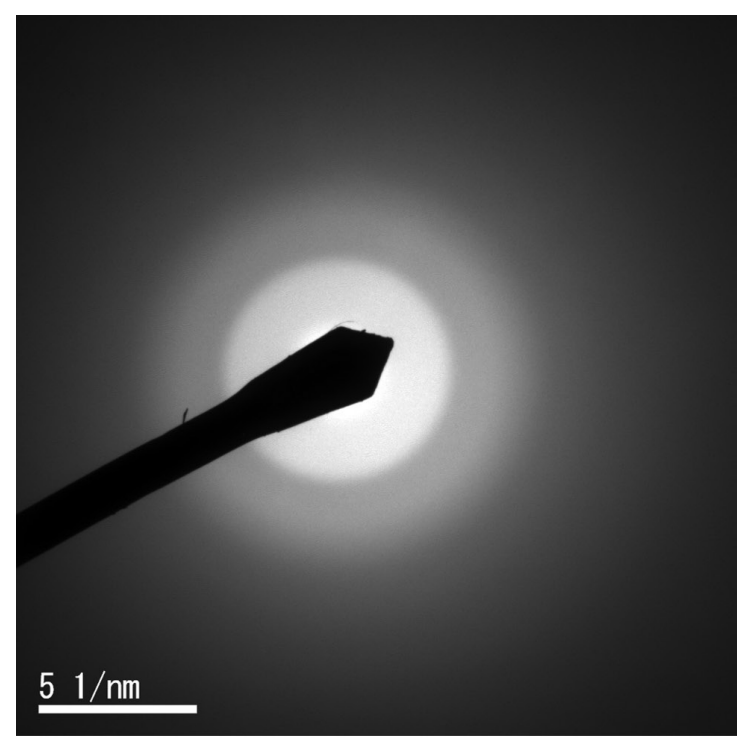

(a)

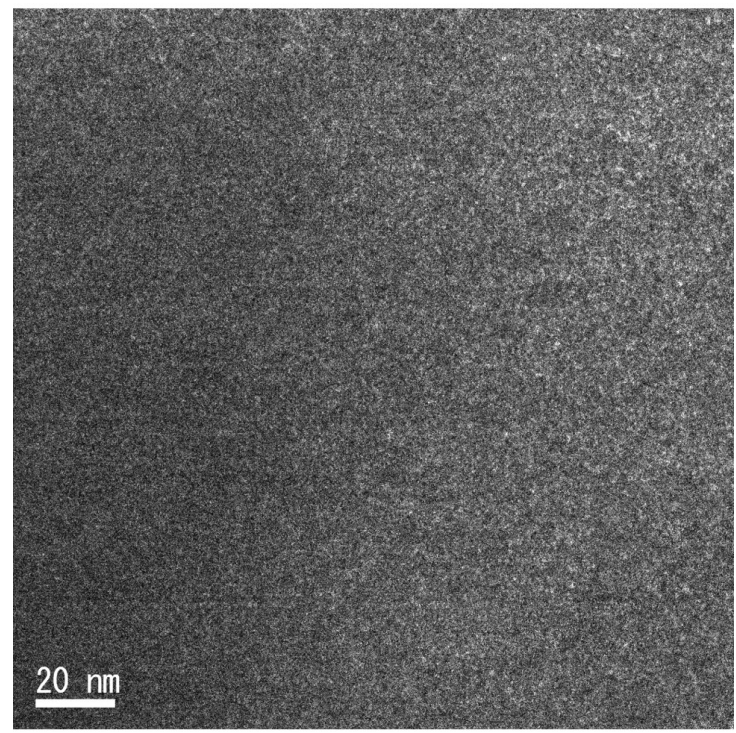

(b)

Figure 3. TEM images of $\mathrm{Fe}_{90} \mathrm{Si}_{5} \mathrm{~B}_{5}$ ribbon: (a) SAED of diffuse halo; (b) Dark-field images. 


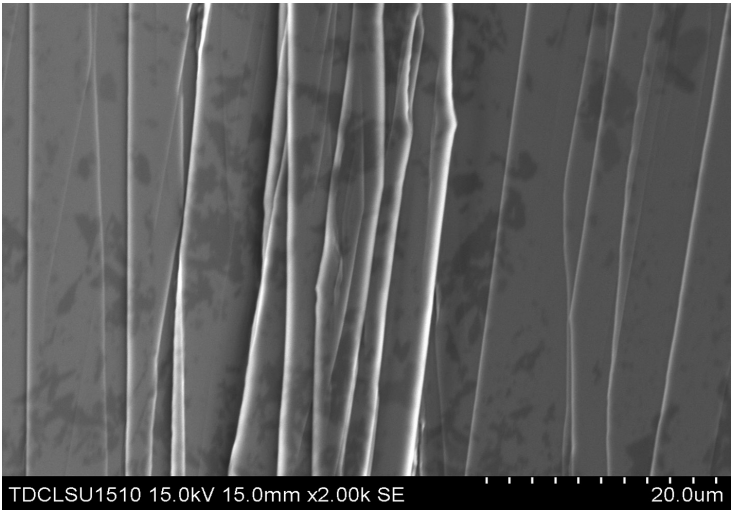

Figure 4. SEM images of surface appearance with shear bands of $\mathrm{Fe}_{90} \mathrm{Si}_{5} \mathrm{~B}_{5}$ ribbon after bending.

of shear bands are introduced, but no appreciable crack is observed. It is noticed that the deformation mode caused by shear bands agrees well with that for ductile amorphous alloys, in spite of distinct difference in their structures ${ }^{16}$.

Figure 5 shows Vickers hardness of the as-spun $\mathrm{Fe}_{90} \mathrm{Si}_{10-\mathrm{x}} \mathrm{B}_{\mathrm{x}}$ $(x=2.5,5$ and 7.5$)$ ribbons as a function of $B$ content, together with the data on bending ductility. The hardness increases almost linearly with increasing B content from 366 at $2.5 \% \mathrm{~B}$ to 632 at $7.5 \% \mathrm{~B}$ through 535 at $5 \% \mathrm{~B}$. Besides, the ductile to brittle transition takes place in the $\mathrm{B}$ content range between 5 at $\% \mathrm{~B}$ to 7.5 at $\% \mathrm{~B}$ corresponding to the Vickers hardness value of about 550 to 600 . Judging from the coexistent structure of bcc- $\mathrm{Fe}(\mathrm{Si})+\mathrm{Fe}_{3} \mathrm{~B}+$ amorphous phases for $\mathrm{Fe}_{90} \mathrm{Si}_{5} \mathrm{~B}_{5}$ alloy, the precipitation of $\mathrm{Fe}_{3} \mathrm{~B}$ in bcc- $\mathrm{Fe}(\mathrm{Si})$ matrix phase does not affect very harmful influence on the bending ductility.

Figure 6 shows tensile stress-elongation curves of the as-spun $\mathrm{Fe}-\mathrm{Si}-\mathrm{B}$ ribbons showing good bending ductility. The tensile fracture strength is the highest (1028 MPa) for $\mathrm{Fe}_{90} \mathrm{Si}_{5} \mathrm{~B}_{5}$, followed by $875 \mathrm{MPa}$ for $\mathrm{Fe}_{91} \mathrm{Si}_{4.5} \mathrm{~B}_{4.5}, 838 \mathrm{MPa}$ for $\mathrm{Fe}_{90} \mathrm{Si}_{7.5} \mathrm{~B}_{2.5}$ and then $656 \mathrm{MPa}$ for $\mathrm{Fe}_{92} \mathrm{Si}_{4} \mathrm{~B}_{4}$. Thus, the tensile fracture strength is dependent on both $\mathrm{Fe}$ and $\mathrm{B}$ contents. Considering that the as-quenched structure is bcc- $\mathrm{Fe}(\mathrm{Si})+\mathrm{Fe}_{3} \mathrm{~B}+$ amorphous phases only for $\mathrm{Fe}_{90} \mathrm{Si}_{5} \mathrm{~B}_{5}$ while the other three alloys are composed of bcc-Fe( $\mathrm{Si}, \mathrm{B})$ containing a trace of amorphous phase, the much higher strength of the $\mathrm{Fe}_{90} \mathrm{Si}_{5} \mathrm{~B}_{5}$ alloy is due to the precipitation of $\mathrm{Fe}_{3} \mathrm{~B}$ phase resulting from the highest $\mathrm{B}$ content.

We further examined the annealing effect on the tensile strength and bending ductility for the $\mathrm{Fe}_{90} \mathrm{Si}_{5} \mathrm{~B}_{5}$ alloy ribbons with the highest tensile fracture strength and good bending ductility in the as-quenched state. Figure 7 shows tensile stress-elongation curves of the $\mathrm{Fe}-\mathrm{Si}$-B ribbons annealed for $900 \mathrm{~s}$ at 623 and $823 \mathrm{~K}$. The data of the as-spun ribbon are also shown for comparison. The ribbons keep good bending ductility after annealing up to $823 \mathrm{~K}$. It is noticed that the yield strength, tensile fracture strength and plastic elongation increase with increasing annealing temperature and reach about $1050 \mathrm{MPa}, 1286 \mathrm{MPa}$ and $0.62 \%$, respectively, after annealing at $823 \mathrm{~K}$. The Vickers hardness also shows a linear increase with increasing annealing temperature, i.e., 541 at $623 \mathrm{~K}$ and 549 at $823 \mathrm{~K}$.

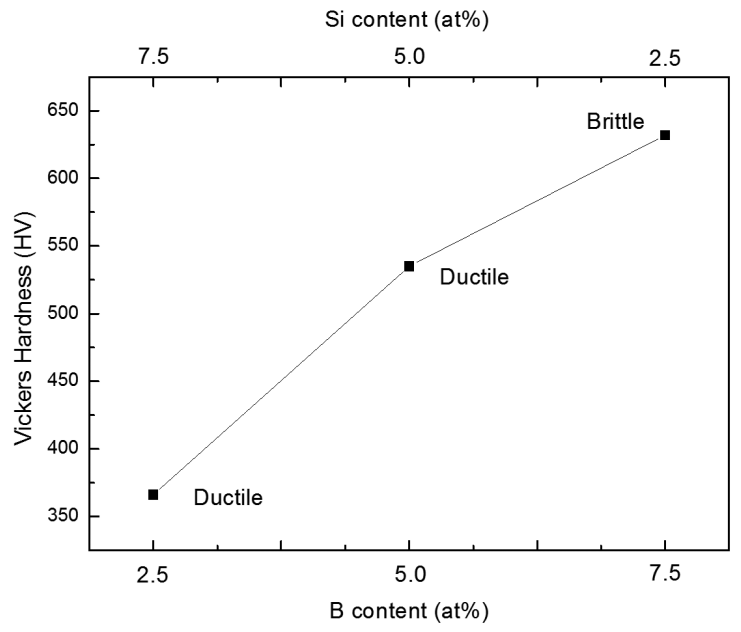

Figure 5. Compositional dependence of Vickers Hardness and bending ductility for the alloy at the same total metalloid content of $\mathrm{Fe}_{90} \mathrm{Si}_{\mathrm{x}} \mathrm{B}_{10-\mathrm{x}}(\mathrm{x}=2.5,5,7.5)$.

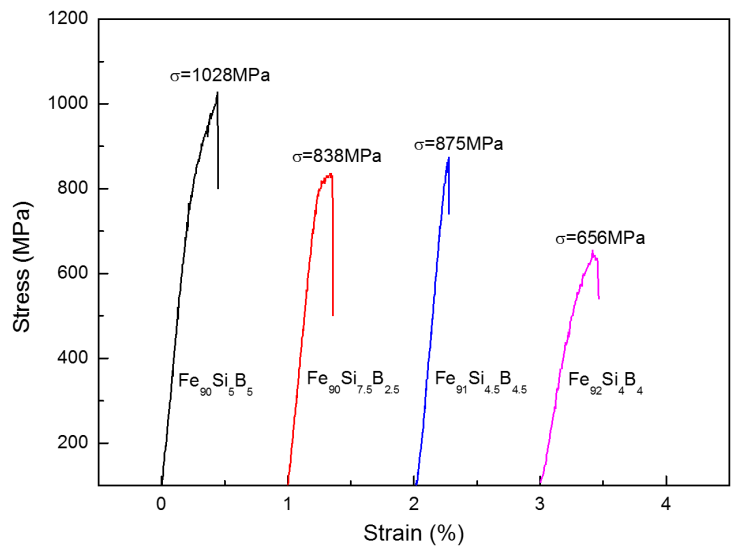

Figure 6. Tensile curve of the ductile Fe-Si-B ribbon alloys with a strain rate of $0.04 \mathrm{~s}^{-1}$.

In order to clarify the reason for the increase in mechanical properties upon annealing, the annealed structure was examined by X-ray diffraction and TEM analyses. Figure 8 shows the X-ray diffraction pattern and bright-field TEM image of the $\mathrm{Fe}_{90} \mathrm{Si}_{5} \mathrm{~B}_{5}$ alloy ribbon annealed for $900 \mathrm{~s}$ at $823 \mathrm{~K}$, together with the data of the X-ray diffraction pattern for the as-spun ribbon. In comparison of the X-ray diffraction pattern shown in Figure 1a and the TEM image shown in Figure 2a for the as-spun ribbon, one cannot see any distinct difference in the X-ray diffraction pattern and the bright-field image between the as-spun and the annealed ribbons. Besides, we could not recognize any halo ring pattern for the annealed sample, being different from the recognized state of amorphous phase in the as-spun ribbon. Therefore, the improvement of mechanical properties is presumably due to the increase in the precipitation amount of $\mathrm{Fe}_{3} \mathrm{~B}$ phase and the reduction of internal strain among their constituent phases through the decomposition of amorphous phase to bcc- $\mathrm{Fe}(\mathrm{Si})$ and $\mathrm{Fe}_{3} \mathrm{~B}$ phases. 


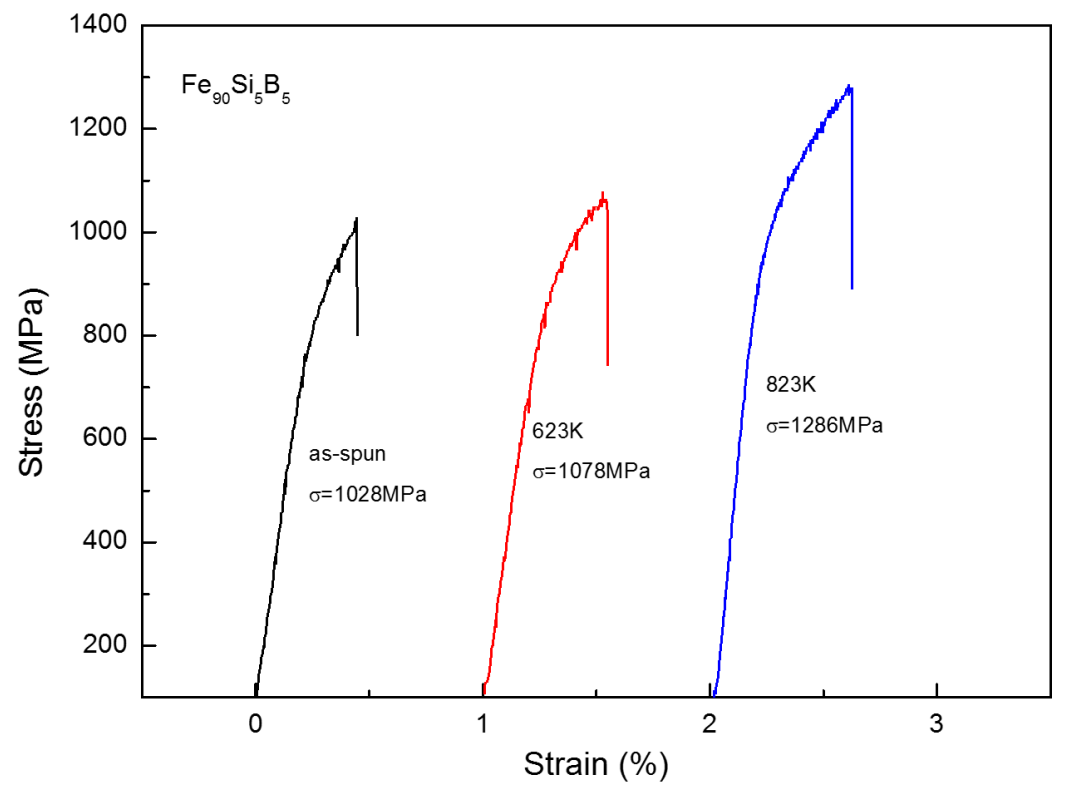

(a)
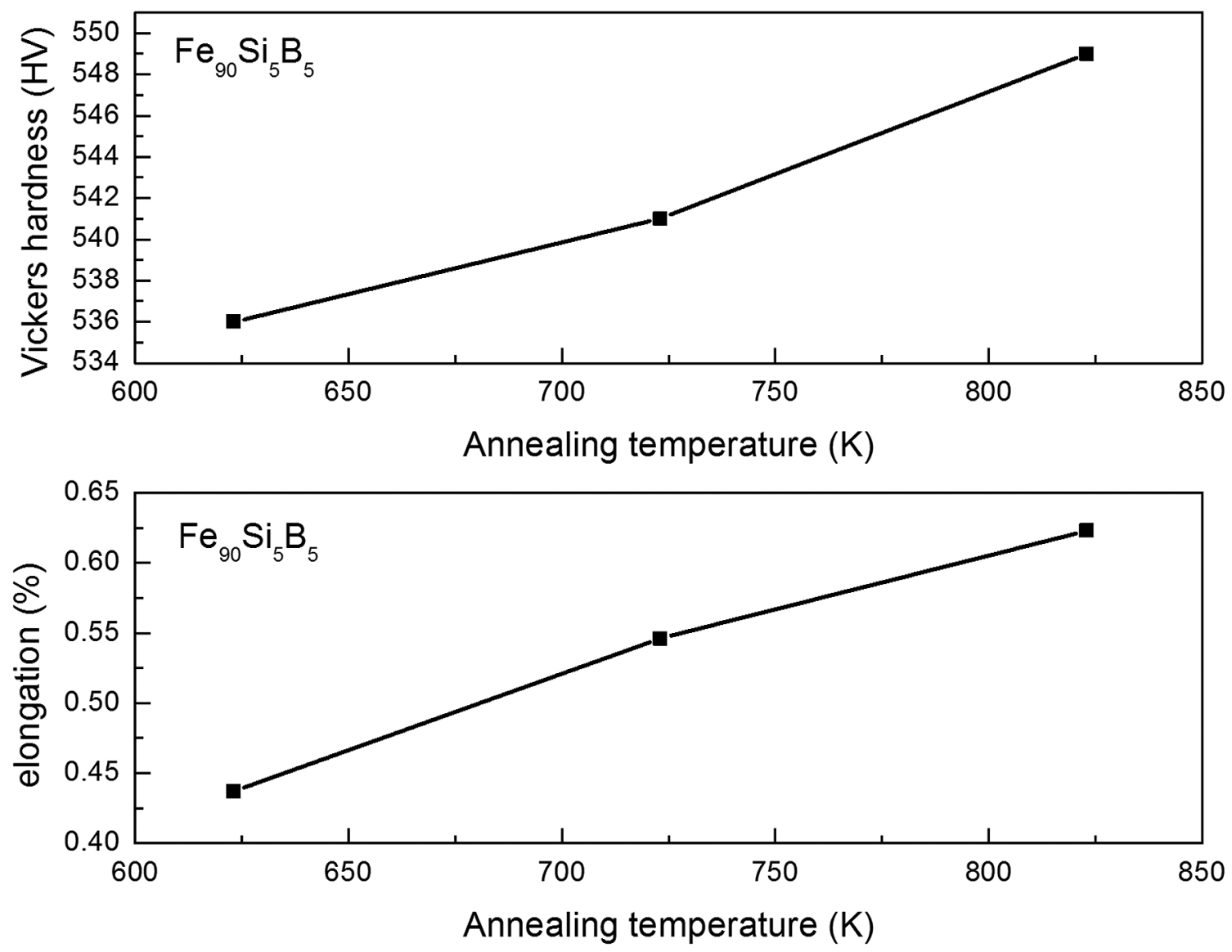

(b)

Figure 7. (a) Tensile curve of the $\mathrm{Fe}_{90} \mathrm{Si}_{5} \mathrm{~B}_{5}$ ribbon alloys with a strain rate of $0.04 \mathrm{~s}^{-1}$ for as-spun state, after annealing at $623 \mathrm{~K}$ and $823 \mathrm{~K}$, respectively; (b) Plots of Vickers hardness - annealing temperature vs. elongation - annealing temperature of $\mathrm{Fe}_{90} \mathrm{Si}_{5} \mathrm{~B}_{5}$ ribbon alloys of as-spun state, after annealing at $623 \mathrm{~K}$ and $823 \mathrm{~K}$, respectively. 


\subsection{Magnetic properties}

Figure $9 \mathrm{a}$ and $9 \mathrm{~b}$ show field-magnetization plots of the melt-spun $\mathrm{Fe}_{90} \mathrm{Si}_{10-\mathrm{x}} \mathrm{B}_{\mathrm{x}}(\mathrm{x}=2.5,5$ and 7.5) ribbons in as-spun and annealed ( $900 \mathrm{~s}$ at $823 \mathrm{~K}$ ) states, respectively.

The saturation magnetization is as high as 1.88 to $1.91 \mathrm{~T}$ in the as-spun state and 1.90 to $1.92 \mathrm{~T}$ in the annealed state. Besides, the initial permeability is evaluated to be approximately 150 . Among the as-spun ribbons, the $\mathrm{Fe}_{90} \mathrm{Si}_{5} \mathrm{~B}_{5}$ ribbon exhibits the highest saturation magnetization. However, the difference is not distinct and the reason for the slight difference remains unknown in the present study.

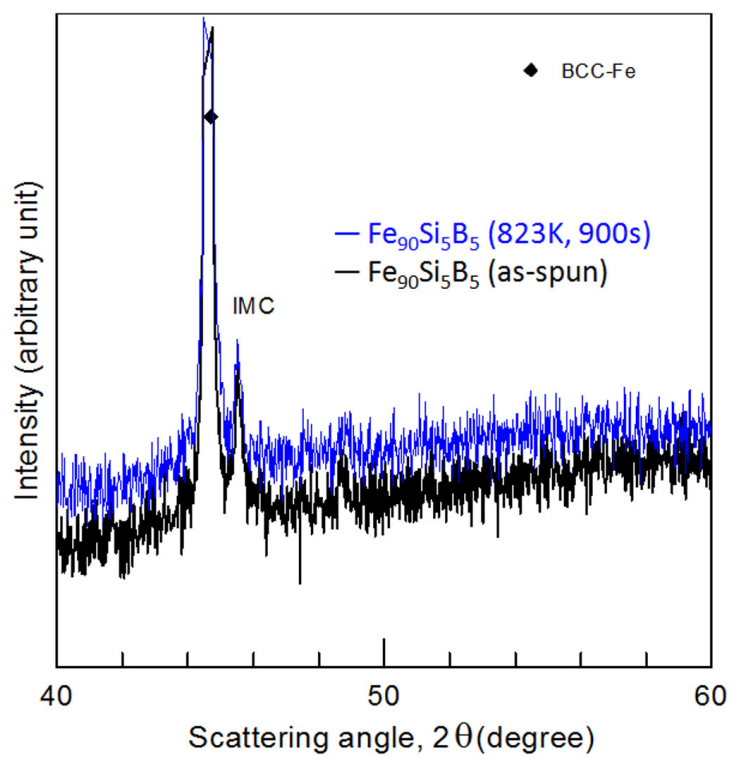

(a)

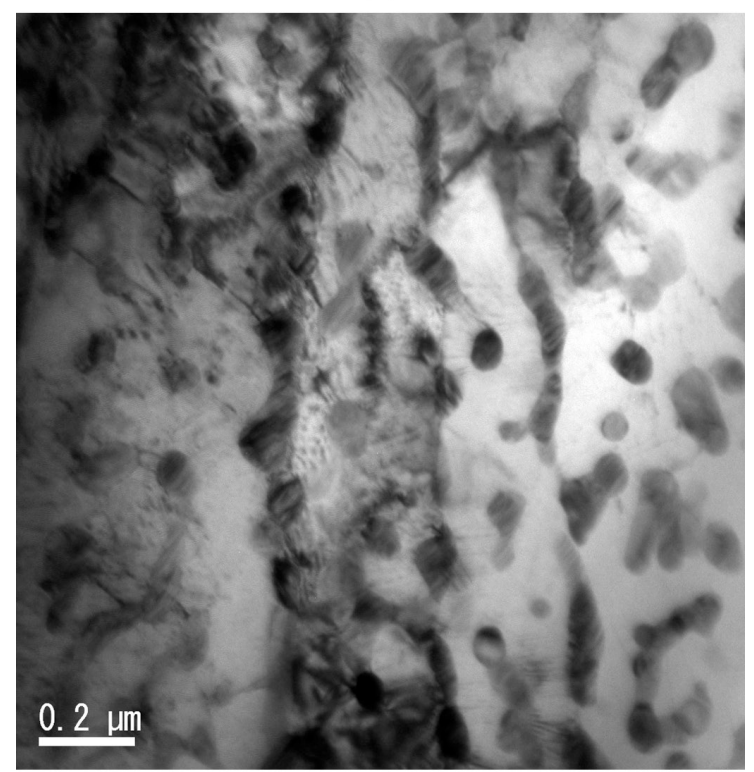

(b)

Figure 8. (a) High resolution XRD patterns $(\mathrm{Cu}-\mathrm{K} \alpha, \lambda=1.5406)$ of $\mathrm{Fe}_{90} \mathrm{Si}_{5} \mathrm{~B}_{5}$ ribbon at as-spun state and after annealing at $823 \mathrm{~K}$; (b) TEM Bright-field image of $\mathrm{Fe}_{90} \mathrm{Si}_{5} \mathrm{~B}_{5}$ ribbon after annealing at $823 \mathrm{~K}$.
The coercivity of the $\mathrm{Fe}_{90} \mathrm{Si}_{5} \mathrm{~B}_{5}$ ribbons was measured as $745 \mathrm{~A} / \mathrm{m}$ for the as-spun state, $743 \mathrm{~A} / \mathrm{m}$ after annealing for $900 \mathrm{~s}$ at $973 \mathrm{~K}$ and $610 \mathrm{~A} / \mathrm{m}$ after annealing for $900 \mathrm{~s}$ at $1073 \mathrm{~K}$.It is thus characterized that the $\mathrm{Fe}_{90} \mathrm{Si}_{5} \mathrm{~B}_{5}$ alloy ribbon exhibits very high saturation magnetization, relatively high initial permeability and moderately high coercivity. The Fe-Si-B alloy with such unique soft magnetic properties is expected to exhibit a nearly constant high permeability in a rather high magnetic field up to coercive field which is useful for application of magnetic sensor in a rather wide magnetic field.

\subsection{Corrosion behavior}

We measured corrosion behavior of the as-spun Fe-Si-B alloy ribbons with good bending ductility in $\mathrm{NaCl}$ aqueous solution. Table 1 summarizes corrosion weight losses of the four ductile Fe-Si-B alloy ribbons. It is noticed that the $\mathrm{Fe}_{90} \mathrm{Si}_{5} \mathrm{~B}_{5}$ ribbon exhibits the best corrosion resistance as compared with the other three alloy ribbons. The difference may be due to the lower Fe content and higher B content. Besides, the fine and homogeneous structure caused by the precipitation of $\mathrm{Fe}_{3} \mathrm{~B}$ compound may be effective for the achievement of better corrosion resistance.

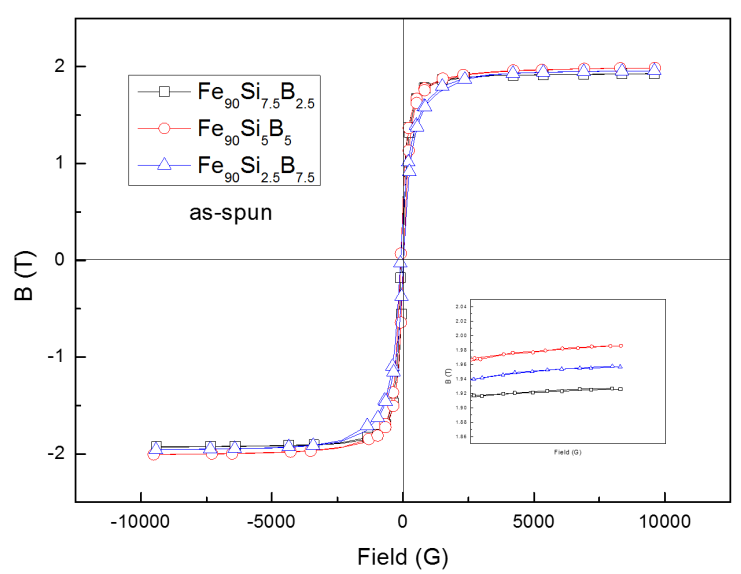

(a)

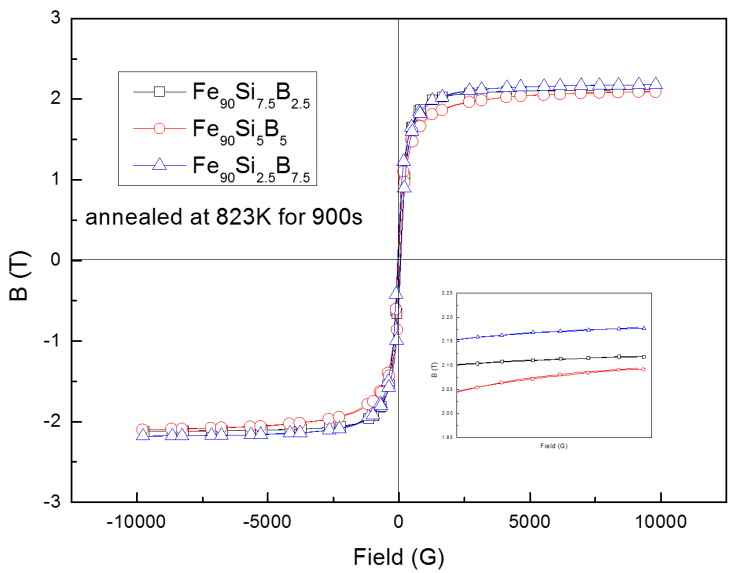

(b)

Figure 9. Field-magnetization plot of $\mathrm{Fe}_{90} \mathrm{Si}_{5} \mathrm{~B}_{5}, \mathrm{Fe}_{90} \mathrm{Si}_{2.5} \mathrm{~B}_{7.5}$ and $\mathrm{Fe}_{90} \mathrm{Si}_{7.5} \mathrm{~B}_{2.5}$ ribbon as-spun alloys: (a) as-spun and (b) annealed at $823 \mathrm{~K}$ for 900 s. 


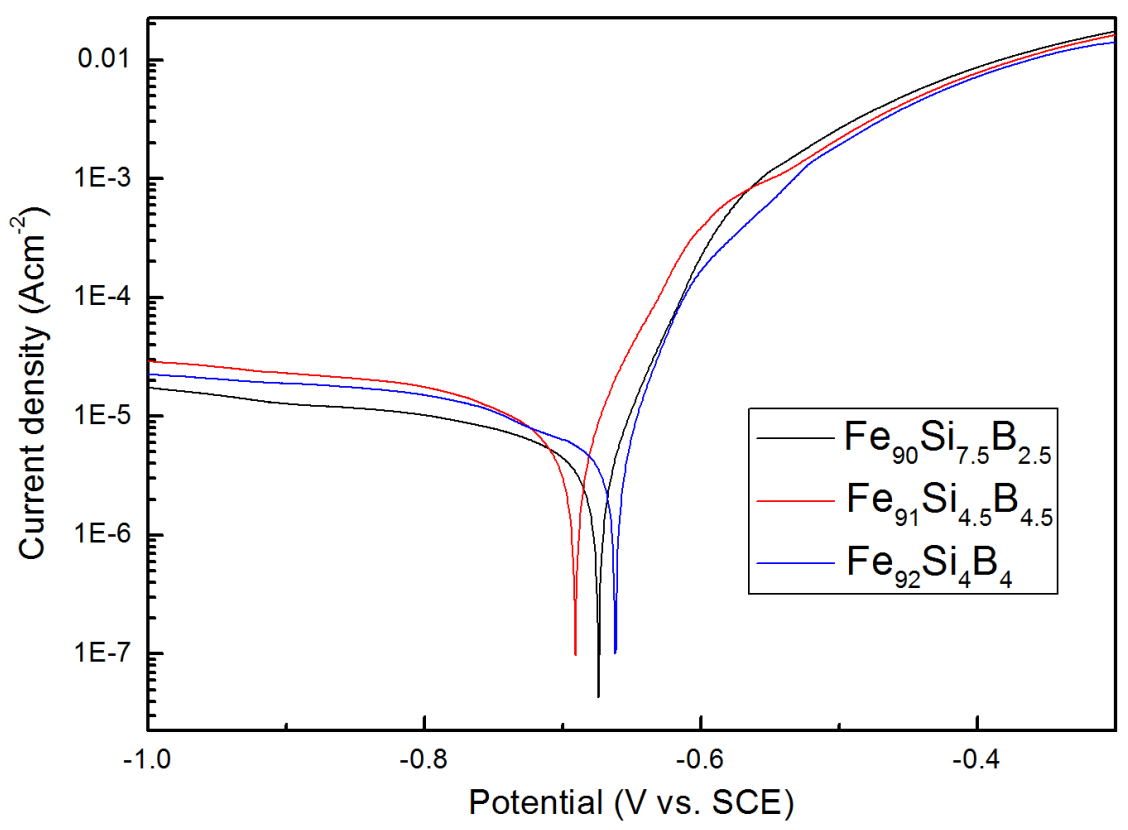

(a)
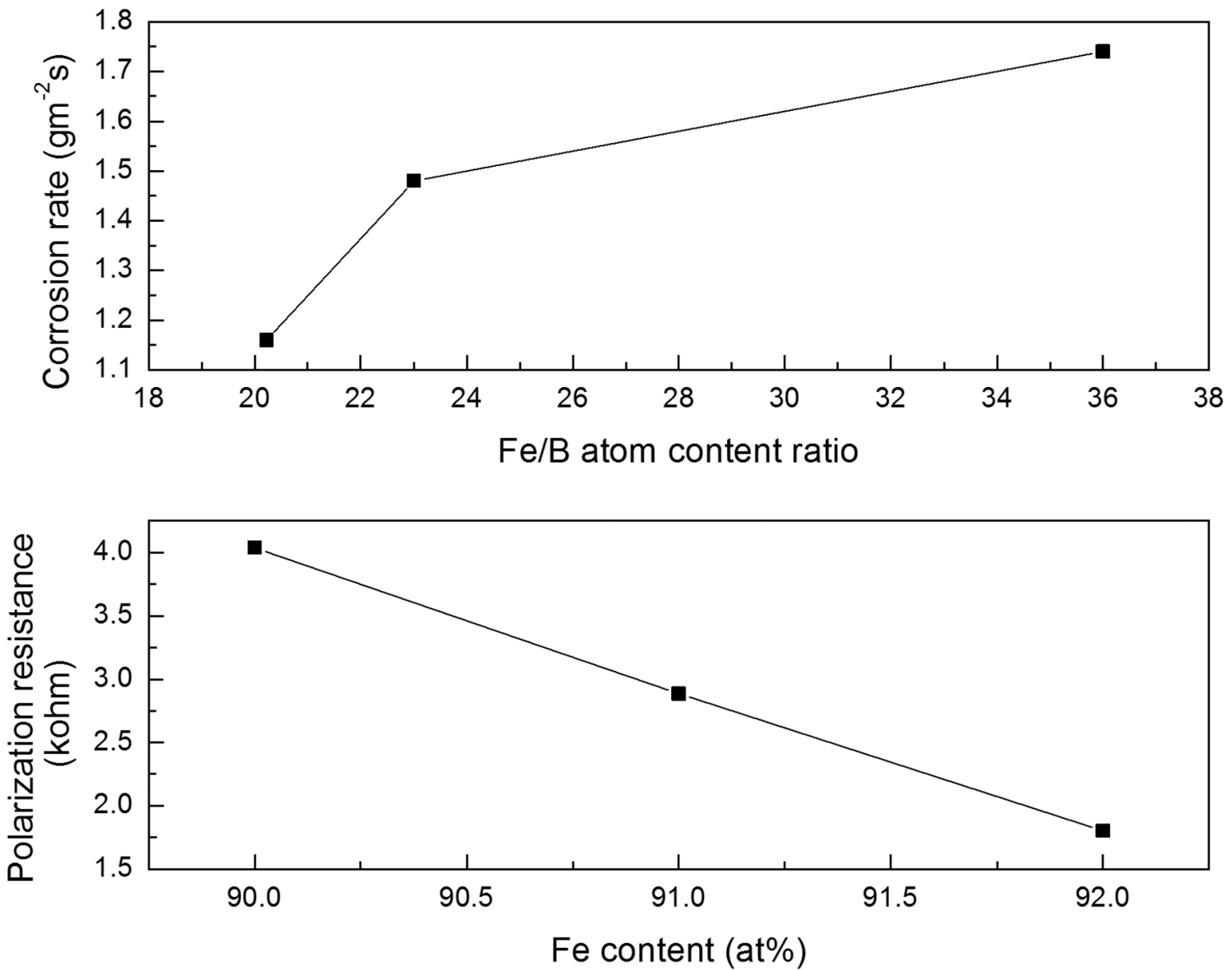

(b)

Figure 10. (a) Polarization curves of $\mathrm{Fe}_{90} \mathrm{Si}_{7.5} \mathrm{~B}_{2.5}, \mathrm{Fe}_{91} \mathrm{Si}_{4.5} \mathrm{~B}_{4.5}$ and $\mathrm{Fe}_{92} \mathrm{Si}_{4} \mathrm{~B}_{4}$ ribbon alloys in $3.5 \mathrm{mass} \% \mathrm{NaCl}$ solution at 298K; (b) Plots of corrosion rate $-\mathrm{Fe} / \mathrm{B}$ atom content ratio vs. Polarization resistance $-\mathrm{Fe}$ content. 
Table 1. Corrosion rate obtained from weight losses and electrochemistry parameters of $\mathrm{Fe}_{90} \mathrm{Si}_{2.5} \mathrm{~B}_{7.5}, \mathrm{Fe}_{90} \mathrm{Si}_{5} \mathrm{~B}_{5}, \mathrm{Fe}_{90} \mathrm{Si}_{7.5} \mathrm{~B}_{2.5}, \mathrm{Fe}_{91} \mathrm{Si}_{4.5} \mathrm{Si}_{4.5}$ and $\mathrm{Fe}_{92} \mathrm{Si}_{4} \mathrm{~B}_{4}$ alloy ribbons measured in $3.5 \mathrm{wt} \% \mathrm{NaCl}$ at $298 \mathrm{~K}$.

\begin{tabular}{ccccc}
\hline Composite & $\begin{array}{c}\text { Corrosion rate } \\
\left(\mathbf{g m}^{-2} \mathbf{s}\right)\end{array}$ & $\begin{array}{c}\text { Polarization resistance } \\
(\mathbf{k o h m})\end{array}$ & $\begin{array}{c}\text { Corrosion current } \\
\text { density }\left(\boldsymbol{\mu} \mathbf{A} / \mathbf{c m}^{2}\right)\end{array}$ & $\begin{array}{c}\text { Corrosion potential } \\
(\mathbf{m V} \mathbf{~ v s . ~ S C E})\end{array}$ \\
\hline $\mathrm{Fe}_{90} \mathrm{Si}_{5} \mathrm{~B}_{5}$ & $1.03 \mathrm{e}-4$ & 4.314 & 15.63 & -706 \\
$\mathrm{Fe}_{90} \mathrm{Si}_{2.5} \mathrm{~B}_{7.5}$ & $1.21 \mathrm{e}-4$ & 4.462 & 17.48 & -690 \\
$\mathrm{Fe}_{90} \mathrm{Si}_{7.5} \mathrm{~B}_{2.5}$ & $1.74 \mathrm{e}-4$ & 4.037 & 19.33 & -674 \\
$\mathrm{Fe}_{91} \mathrm{Si}_{4.5} \mathrm{~B}_{4.5}$ & $1.16 \mathrm{e}-4$ & 2.884 & 16.37 & -691 \\
$\mathrm{Fe}_{92} \mathrm{Si}_{4} \mathrm{~B}_{4}$ & $1.48 \mathrm{e}-4$ & 1.803 & 16.82 & -662 \\
\hline
\end{tabular}

Figure 10a shows some polarization curves of the as-spun alloy ribbons. Table 1 also summarizes electrochemistry data obtained from the polarization curves. It is seen that the polarization resistance decreases with increasing $\mathrm{Fe}$ content while the corrosion current density increases with an increase of $\mathrm{Fe} / \mathrm{B}$ ratio as shown in Figure 10b. It is therefore concluded that the corrosion resistance is significantly dependent on the concentration ratio of $\mathrm{Fe}$ to metalloid and decreases with increasing the ratio, in agreement with previous other works ${ }^{17,18}$

\section{Conclusion}

We examined the structure, thermal stability, mechanical properties, magnetic properties and corrosion behavior of melt-spun $\mathrm{Fe}_{90} \mathrm{Si}_{10}-\mathrm{xBx}\left(\mathrm{x}=2.5,5\right.$ and 7.5), $\mathrm{Fe}_{91} \mathrm{Si}_{4.5} \mathrm{~B}_{4.5}$ and $\mathrm{Fe}_{92} \mathrm{Si}_{4} \mathrm{~B}_{4}$ alloy ribbons, with the aim of developing a new functional $\mathrm{Fe}$-based alloy. The results obtained are summarized:

(1) The as-spun structure consists of bcc-Fe( $\mathrm{Si})+\mathrm{Fe}_{3} \mathrm{~B}$ + amorphous phases for $\mathrm{Fe}_{90} \mathrm{Si}_{5} \mathrm{~B}_{5}$ and $\mathrm{Fe}_{90} \mathrm{Si}_{2.5} \mathrm{~B}_{7.5}$ alloys and bcc-Fe + amorphous for $\mathrm{Fe}_{90} \mathrm{Si}_{7.5} \mathrm{~B}_{2.5}$, $\mathrm{Fe}_{91} \mathrm{Si}_{4.5} \mathrm{~B}_{4.5}$ and $\mathrm{Fe}_{92} \mathrm{Si}_{4} \mathrm{~B}_{4}$ alloys.

(2) The as-spun Fe-Si-B alloy ribbons except $\mathrm{Fe}_{90} \mathrm{Si}_{2.5} \mathrm{~B}_{7.5}$ exhibit good bending ductility. The Vickers hardness of the ductile ribbon alloys increase distinctly with increasing B content and decreasing Fe content.

\section{References}

1. Makino A, Bitoh T, Kojima A, Inoue A and Masumoto T. Low core losses of nanocrystalline $\mathrm{Fe}-\mathrm{Zr}-\mathrm{Nb}-\mathrm{B}$ soft magnetic alloys with high magnetic flux density. Materials Science and Engineering A. 2001; 304-306:1083-1086. http://dx.doi. org/10.1016/S0921-5093(00)01761-5.

2. Makino A, Bitoh T, Kojima A, Inoue A and Masumoto T. Magnetic properties of zero-magnetostrictive nanocrystalline $\mathrm{Fe}-\mathrm{Zr}-\mathrm{Nb}-\mathrm{B}$ soft magnetic alloys with high magnetic induction. Journal of Magnetism and Magnetic Materials. 2000; 215-216:288-292. http://dx.doi.org/10.1016/S0304-8853(00)00136-0.

3. Makino A, Inoue A and Masumoto T. Nanocrystalline soft magnetic $\mathrm{Fe}-\mathrm{M}-\mathrm{B}(\mathrm{M}=\mathrm{Zr}, \mathrm{Hf}, \mathrm{Nb}), \mathrm{Fe}-\mathrm{M}-\mathrm{O}(\mathrm{M}=\mathrm{Zr}$, Hf, rare earth) alloys and their applications.. Nanostructured Materials. 1999; 12(5-8):825-828. http://dx.doi.org/10.1016/ S0965-9773(99)00244-5.

4. Sokol-Kutylovskij OL. Magnetic-field sensors based on amorphous alloys for high-sensitivity low-frequency measurements. Sensors
(3) The tensile strength exhibitsthe similar compositional dependence as hardness and the highest value was $1028 \mathrm{MPa}$ for $\mathrm{Fe}_{90} \mathrm{Si}_{5} \mathrm{~B}_{5}$ alloy.

(4) The annealing at $823 \mathrm{~K}$ for $\mathrm{Fe}_{90} \mathrm{Si}_{5} \mathrm{~B}_{5}$ alloy caused significant increases in tensile fracture strength to $1286 \mathrm{MPa}$, tensile elongation to $0.62 \%$ and Vickers hardness to 549 . Their increases seem to be related to the decomposition of the remaining amorphous phase to bcc-Fe( $\mathrm{Si}$ ) and $\mathrm{Fe}_{3} \mathrm{~B}$ phases.

(5) The $\mathrm{Fe}_{90} \mathrm{Si}_{5} \mathrm{~B}_{5}$ alloy ribbons exhibit very high saturation magnetization of $1.91 \mathrm{~T}$, rather large initial permeability of 150 and moderately large coercivity of 610 to $745 \mathrm{~A} / \mathrm{m}$, suggesting the existence of a nearly constant high permeability in an applied field up to the coercive field.

(6) The corrosion resistance of the ductile Fe-Si-B ribbons increases with increasing the concentration ratio of $\mathrm{B} / \mathrm{Fe}$ and with decreasing Fe content.

Owing to the unique metastable structure, good mechanical properties, unique soft magnetic properties and relatively high corrosion resistance, the melt-spun $\mathrm{Fe}-\mathrm{Si}$-B alloy ribbons are encouraging as a future magnetic sensor material.

\section{Acknowledgements}

The present research is partially supported by China Postdoctoral Fund (2014M560186).

and Actuators A: Physical. 1997; 62(1-3):496-500. http://dx.doi. org/10.1016/S0924-4247(97)01505-7.

5. Barandiaran JM and Gutierrez J. Magnetoelastic sensors based on soft amorphous magnetic alloys. Sensors and Actuators A: Physical. 1997; 59(1-3):38-42. http://dx.doi.org/10.1016/ S0924-4247(97)80145-8

6. Szewieczek D, Baron A and Nawrat G. Electrochemical behavior of Fe78Si9B13 alloy in sulphate and chloride solution. Journal of Materials Processing Technology. 2006; 175(1-3):411-415. http://dx.doi.org/10.1016/j.jmatprotec.2005.04.004.

7. Makino A, Kubota T, Makabe M, Chang CT and Inoue A. FeSiBP metallic glasses with high glass-forming ability and excellent magnetic properties. Materials Science and Engineering B. 2008; 148(1-3):166-170. http://dx.doi.org/10.1016/j.mseb.2007.09.010.

8. Chang CT, Kubota T, Makino A and Inoue A. Synthesis of ferromagnetic Fe-based bulk glassy alloys in the Fe-Si-B-P-C system. Journal of Alloys and Compounds. 2009; 473:368-372. 
9. Luborsky F, Walter J. Iron-boron-silicon ternary amorphous alloys. US Patent US4217135 A. 1978 Nov. 29.

10. Han Y, Kong FL, Chang CT, Zhu SL, Inoue A, Shalaan ES and Al-Marzouki F. Syntheses and corrosion behaviors of Febased amorphous soft magnetic alloys with high-saturation magnetization near 1.7 T. Journal of Materials Research. 2015; 30(4):547-555.

11. Lashgan HR, Chu D, Xie S, Sun H, Ferry M and Li S. Composition dependence of the microstructure and soft magnetic properties of Fe-based amorphous/nanocrystalline alloys: a review study. Journal of Non-Crystalline Solids. 2014; 391:61-82. http:// dx.doi.org/10.1016/j.jnoncrysol.2014.03.010.

12. Major RV, Jasko TM and Cruickshank KJ. Development of amorphous Fe-B based alloys for choke and inductor applications. IEEE Transactions on Magnetics. 1984; 20(5):1415-1416.

13. Okazaki Y, Kitagawa H, Yanase S and Handa S. Constant permeability properties of Fe-based amorphous ribbon with inorganic coating. Journal of Magnetism and Magnetic Materials. 2000; 215-216:328-330. http://dx.doi.org/10.1016/ S0304-8853(00)00149-9.

14. Chiriac $\mathrm{H}$ and Hison $\mathrm{C}$. Mechanical behavior of nanocrystalline Fe-Hf-B ribbons. Journal of Magnetism and Magnetic
Materials. 2003; 254-255:475-476. http://dx.doi.org/10.1016/ S0304-8853(02)00871-5.

15. Daniil M, Ohodnicki PR, McHenry ME and Willard MA. Shear band formation and fracture behavior of nanocrystalline ( $\mathrm{Co}, \mathrm{Fe})$ based alloys. Philosophical Magazine. 2010; 90(12):1547-1565. http://dx.doi.org/10.1080/14786430903405512.

16. Conner RD, Johnson WL, Paton NE and Nix WD. Shear bands and cracking of metallic glass plates in bending. Journal of Applied Physics. 2003; 94(2):904-911. http://dx.doi. org/10.1063/1.1582555.

17. Long ZL, Shao Y, Deng XH, Zhang ZC, Jiang Y, Zhang $\mathrm{P}$, et al. Cr effects on magnetic and corrosion properties of $\mathrm{Fe}-\mathrm{Co}-\mathrm{Si}-\mathrm{B}-\mathrm{Nb}-\mathrm{Cr}$ bulk glassy alloys with high glass-forming ability. Intermetallics. 2007; 15(11):1453-1458. http://dx.doi. org/10.1016/j.intermet.2007.05.002.

18. Pang SJ, Zhang T, Asami K and Inoue A. Bulk glassy Fe-CrMo-C-B alloys with high corrosion resistance. Corrosion Science. 2002; 44(8):1847-1856. http://dx.doi.org/10.1016/ S0010-938X(02)00002-1. 